\title{
MAPA-MÚNDI: desafios da antropologia do século $\mathrm{XXI}^{*}$
}

\author{
Marco Antonio Rossi
}

\author{
Aluno do Curso de Especialização em Sociologia e Sociologia da Educação \\ da Universidade Estadual de Londrina.
}

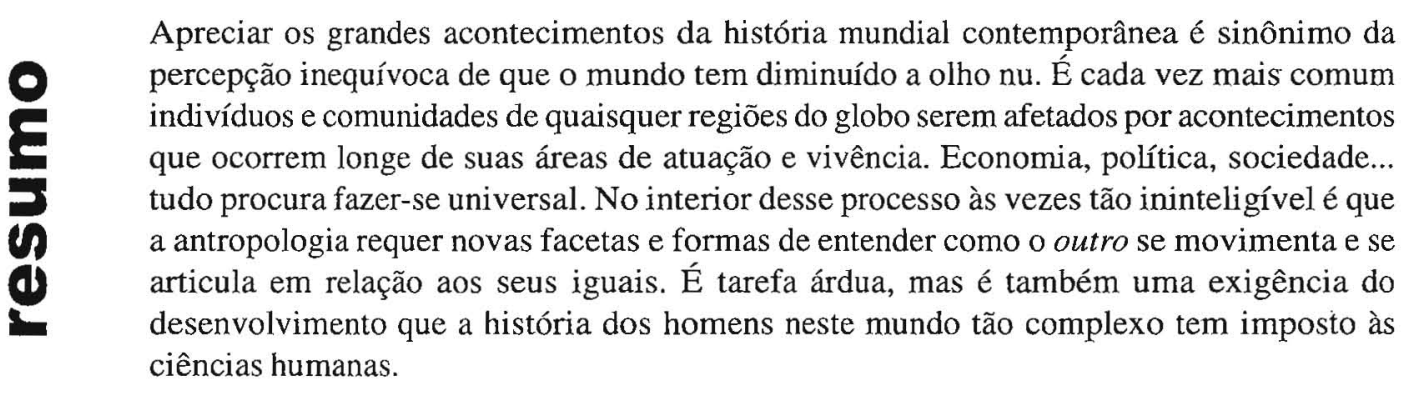

Palavras-chave: sobremodernidade; cidadania; democracia; lugares e não-lugares; mercadorias; espaços públicos.

\section{UM BREVE CELEBRAR DE NOSSO TEMPO...}

$\mathbf{N}$

o dicionário de língua francesa Petit Robert, a palavra modernidade apresenta-se com dois sentidos, ambos complementares, indicando um significado de ruptura: representa tudo aquilo que nega o antigo, o arcaico, o velho, e, numa linguagem filosófica, caracteriza os tempos sociais que se sobrepuseram ao chamado Antigo Regime, o período da humanidade conhecido como feudal. Nesses termos, viveríamos ainda hoje nos tempos modernos, porque o Estado pautado em linhas racionais de conduta humana, social, contrapondose às linhas hereditárias que asseguravam o poder dos monarcas e senhores feudais, vem marcando, ao longo dos séculos XVI, XVII, XVIII e XIX, sua presença num mundo em que as relações econômicas, as utopias políticas, o desenvolvimento da ciência e a diversidade das manifestações culturais constroem, cada vez mais, um planeta em permanente interlocução, um espaço social em que as lutas políticas e as "missões civilizadoras" não param de crescer e suscitar dinâmicas e conflitos no palco povoado por indivíduos e grupos de todas as nações, dos quatro cantos do mundo.

O século XX, cujo início, segundo o historiador inglês Eric J. Hobsbawm, se dá em 1914 — período em que a Primeira Guerra Mundial produz inúmeras máculas na tão otimista e promissora Belle Époque -, evocando o surgimento de um mundo em que as grandes utopias de emancipação humana são substituídas por uma desenfreada perda de sentido da vida dos homens: as guerras e revoluções, escreve Hannah Arendt na introdução de Da revolução, passam a marcar o sentido da política de dominação do homem pelo homem e a expressar o papel que as ciências biológicas, exatas e humanas desempenham na consolidação deste mundo do qual os grupos deixam de participar e no qual os indivíduos se fecham cada vez mais em si mesmos, procurando, longe dos espaços constituídos socialmente, dar uma nova orientação às suas vidas.

Das guerras e revoluções se possa talvez retirar a marca maior do século XX, principalmente aquela que vem caracterizando os últimos cinquienta anos da história econômica e política da humanidade, qual seja: a fragmentação do Estado moderno, o qual as guerras e revoluções tanto buscaram fortalecer, e a subseqüente expansão das ordenações econômicas sob parâmetros mundiais. É nesse contexto de

\footnotetext{
* O texto é uma versão integral e pouco modificada de trabalho apresentado para avaliação à disciplina Cultura e Sociedade, ministrada pela professora Kimiye Tommasino, no curso de Especialização em Sociologia e Sociologia da Educação, da UEL, em 1999.
} 
globalização dos mercados econômicos e de tentativa de universalizar "novas" utopias políticas que a antropologia se destaca, pois, no interior desse processo complexo e eminentemente conflituoso e contraditório de leis gerais prescritas para toda a humanidade, a cultura se notabiliza, ganhando um forte revigoramento de reivindicações étnicas locais, circunscritas a regiões distantes e ao mesmo tempo próximas da planetarização das relações sociais da modernidade.

Os processos de consolidação dos Estados modernos marcaram, nas guerras e revoluções do século $\mathrm{XX}$, as cicatrizes profundas de suas fragilidades. Se o ideário do Estado moderno nasce de uma valorização dos ideais individuais, dos direitos civis e políticos conquistados no decorrer dos séculos XVIII e XIX, sua existência, entretanto, sempre se apoiou nas ideologias de grupos, classes e interesses coletivos que travam lutas constantes pelo poder, seja ele simbólico, seja ele efetivo, funcional, estrutural. O Estado e o ideário democrático como "o produto artificial da vontade dos indivíduos", usando uma expressão de Norberto Bobbio, efetivaram-se por seu contraponto: as associações de interesses coletivos, quer fossem políticos, quer fossem econômicos. (MONTERO, 1996, p.105-106)

Pode-se dizer que os últimos vinte anos dessa segunda metade do século XX aceleraram os acontecimentos históricos, difundiram-nos no interior de quase todas as fronteiras e produziram sensíveis transformações, para o bem e para o mal, na vida social de toda a humanidade. Esse é um ponto inegável. O fato, no entanto, é que não se produziu um mundo uniformizado, unitário, por mais que as intenções da expansão econômica capitalista e o desejo das grandes utopias políticas o quisessem. À modernidade sobrepôsse uma nova época, uma sobremodernidade, em que os espaços, o tempo e a individualização do mundo público ganharam novos e múltiplos aspectos. (AUGÉ, 1997, p.114) Assim, os processos tecnológicos que ampliaram e sofisticaram os meios de comunicação, os contatos entre mundos antes tão distintos e distantes se fizeram acompanhar de crises profundas nos meios tradicionais de representação dos grupos humanos, tais como os partidos políticos, os sindicatos e, sua grande projeção e aspiração, o Estado moderno. Conquanto a história se desloque constantemente no tempo e no espaço, visando a produzir uma verdadeira aldeia global, crescem, como paradoxo - palavra emblemática da modernidade desde o advento da razão iluminista — os particularismos e os processos de reafirmação de identidades culturais.

A antropologia - ao revisar os nós górdios de seus velhos paradigmas, como os problemas da totalidade e da investigação (relação entre sujeitos que se espelham: pesquisadores e pesquisados) — vê na cultura a possibilidade de criar linhas-mestras entre o poder e a vida cotidiana, um espaço de análise para o entendimento dos movimentos complexos da contemporaneidade. Ao mesmo tempo, tendo em vista que as sociedades humanas não se reduzem à sua cultura, cabe também à antropologia procurar unir os estudos do poder, das estruturas e dos grandes movimentos econômicos e políticos mundiais a análises simbólicas e de construção das identidades locais para vislumbrar o modo como as tensões entre o global e o local se articulam e passam a produzir culturas em permanente transformação. (cf. MONTERO, 1991, p.123-124; SANTOS, 1994, p.31 e 43)

Repensar o Estado, a cidadania e o processo democrático torna-se tão necessário à antropologia quanto redimensioná-los numa perspectiva que incorpore os inúmeros lugares e formas de construção da identidade que se espalham e, ao mesmo tempo, se aproximam no mundo contemporâneo. Moderno ou pós-moderno, o fato é que o mundo está diferente, e compreendê-lo faz-se primordial para que os campos de investigação antropológica cruzem os oceanos cientes de que o "outro" se desfaz e se refaz. Refazer-se é medida profilática que visa a impedir que a antropologia e as transformações socioculturais da sobremodernidade se assemelhem a aviões que, durante uma forte tempestade, se chocam e se estilhaçam em silêncio.

\section{ADMIRÁVEL MUNDO NOVO: MULTICULTURALIDADES E SINCRETISMOS}

É de grande impacto e relevância a afirmação do sociólogo português Boaventura de Sousa Santos segundo a qual as culturas não são um todo aberto; apresentam espaços próprios e delimitados de penetração, inserção, prolongamentos. Nesse mesmo sentido é possível verificar que a cultura é, hoje em dia, o locus de ação e criação das novas identidades étnicas e locais, uma criação que dá sentido e dinâmica a trajetórias de grupos locais no processo de globalização. (SANTOS, 1994, p.43)

No contexto atual da globalização capitalista, o Estado já não mais se apresenta como constituidor hegemônico das identidades. Abrem-se, pois, portas para a cultura, para as reivindicações locais, para as tentativas de criar novas formas de representação social... Todas essas novas possibilidades, diferentes formas de caminhar e habitar o mundo, revelam uma cultura que, ao mesmo tempo, se abre e se fecha, procurando não regredir - como fizeram o Estado e, no Antigo Regime, a fé - em seu papel de construtora de identidades, locus ideológico de reivindicações num momento em que se encontram em profunda crise os valores e acepções de cidadania. (idem, p.35 e 50)

O princípio da multiculturalidade contemporânea dáse no momento em que a história de aproximação progressiva dos povos e nações se faz através de meios alheios aos homens de uma determinada localidade, de uma cultura de massa, de grandes empreendimentos tecnológicos, visuais, auditivos, captados por satélites e adquiridos, quando se tornam palpáveis, em qualquer estabelecimento comercial do mundo. A mídia televisiva e as mercadorias transcontinentais por ela divulgadas e tidas como essenciais à vida de cada um dos homens transformam os espaços sociais, o trabalho, o papel das famílias, do Estado, da política institucional, etc. Um morador de Caracas, na Venezuela, e um habitante das Ilhas Fiji têm em comum cada vez mais imagens, sons, perfumes, ídolos, sonhos e, principalmente, mercadorias. Da 
mesma forma, têm problemas em comum, agruras de um mundo que permanentemente se desfaz e se põe a nu. $\hat{E}$ impossível escapar ao fato de que somos todos consumidores mundiais. Não somos, entretanto, homens que se identificam do mesmo modo, que buscam soluções iguais ou parecidas, que querem um mesmo mundo, um mesmo uniforme diário e impessoal. O alheio, o longínquo, está, a cada dia, em mais e mais sociedades, mas em cada ponto do mundo são dados a ele uma estética e um significado particulares, embebidos num sincretismo que é distinto em cada cultura.

O sincretismo - que é multicultural e resultado de ações de diáspora, de rompimento com o linear, o tradicional, o herdado, o circunscrito - é a forma pela qual se dá o "borramento" daquilo que vem pronto, degustado, previamente concebido como ideal, útil, intransferível e indelével. É um modo de fazer da história global, vinda às vezes não se sabe de onde, a história de quem a quer de um jeito e não de outro. (CANEVACCI, 1996)

Um dos grandes desafios da antropologia é fazer da macro-história, aqueles acontecimentos colossais que levam a cabo a idéia de inevitabilidade do que acomete os homens e suas culturas, um mapa no qual a cultura refaz o que parecia fixo, previamente mixado nos quatro cantos do mundo. É da antropologia a tarefa de refutar o irrefutável, de ver no sincretismo, nas hibridações culturais, na busca árdua de um marco identitário por todas as sociedades humanas — todas complexas e glocais ${ }^{1}$ - uma definição de cultura não-unitária, conflituosa, contraditória, fruto das identidades que se constroem em espaços múltiplos, virtuais e reais, próximos e distantes no tempo e no espaço. O sincretismo é, pois, um movimento anticíclico, o qual resulta de inquietudes, vontades, de subjetividades que têm na dinâmica de seus apelos culturais a liberdade de que necessitam, sem conceitos previsíveis, sem acontecimentos preestabelecidos. (idem, p.14-17)

À antropologia parece ser mais adequada uma dialética que se contraponha àquela de caráter purificador, homogeneizante, que visa a ordenar e superar dicotomias e conflitos: a dialética sincrética - que se põe radicalmente contra a de tipo sintético, macro-histórico, bipolarizante, maniqueísta, higienizador e civilizador - não quer superar; quer criar espaços novos de interlocução, mistura e fragmentação. A dialética sincrética procura a metodologia de colar, recortar, não superar: é uma dialética híbrida em que coexistem o racional e o irracional, o humano e o animal, o prosaico e o moderno, a linguagem comunicativa e o silêncio, os santos abençoados e os orixás marginalizados, etc. (idem, p.38-39)

Ao procurar a explosão de múltiplas subjetividades, o antropólogo se defronta com sua identidade multicultural de ser humano e de cientista. Nele coexistem e se confundem os processos de sua formação, quer seja ela acadêmica, quer seja ela vivenciada em sua cotidianidade. Assim, é do antropólogo a vasta gama de aprendizados que vão da literatura à informalidade, à oralidade, à necessidade de subjetivar-se e dar àqueles a quem investiga e busca compreender a mesma necessidade, qual seja: a de fazer-se ouvir. Não se trata de uma mera e simples polifonia, na qual as vozes se multiplicam e acreditam por si sós esclarecer dúvidas e anseios. Não. Cabe à ciência algum papel: o método, o rigor, a experiência das análises precedentes e tudo o mais. Marc Augé, pensando na relação entre o antropólogo e o objeto investigado, afirma que o saber científico organizado, cuja essência é a "estranheza" que separa as subjetividades de cientistas e culturas interpretadas, tem seu valor. Não é do cientista nem das vozes que se fazem ouvir o papel do entendimento antropológico. É de sua confluência, dos resultados que são obtidos a partir de seus respectivos papéis no trabalho antropológico. (AUGÉ, 1997)

Da antropologia clássica aprendemos a ouvir o antropólogo; de parte da recente experiência pós-moderna aprendemos a ouvir as múltiplas vozes da cultura que se quis entender. Do amálgama dessas duas experiências retiraremos, quem sabe, uma compreensão bem-construída dos problemas que tomaram de assalto as sociedades humanas no processo de globalização. Dentre tais problemas, destaca-se a questão relativa ao crescimento global dos processos econômicos, do mercado como construtor de identidades, o qual desencadeia crises nos velhos conceitos de cidadania e democracia. Nesse quadro de crises, um espectro tornou-se o marco das sociedades humanas contemporâneas: o de conciliar igualdade e diferença, ou seja, o de ver no outro alguém que é, ao mesmo tempo, próximo e distante, igual e diferente, que tem reivindicações que procuram garantir o direito de existência de sua alteridade. Dos particularismos que crescem à proporção que se buscam novas formas de representação nasce uma necessidade de repensar a cidadania e a democracia, bem como o modo de o mercado integrar o rol dos elementos que ajudam a construir as identidades individuais e coletivas. Esse modo, num mundo em que a modernidade se coloca abaixo de uma nova época, uma época de sobremodernidade, se dá nos velhos lugares antropológicos e no que chama Marc Augé de não-lugares. Há, pois, no mundo glocal, uma proliferação de novos espaços, um redimensionamento do tempo e, consequientemente, uma ampliação do quadro em que se constituíam as identidades e se defrontavam as alteridades sociais. É no exame desse mundo de não-lugares, de diminuição dos espaços públicos, que a antropologia vem projetando novas preocupações e paradigmas.

\section{O PRÓXIMO EM TRÂNSITO: O "NOVO" OBJETO DA ANTROPO- LOGIA}

Em Não-lugares, recente obra do antropólogo francês Marc Augé, há uma indagação instigante dirigida à antropologia do mundo glocal: "os fatos, as instituições, os modos de reagrupamento (de trabalho, de lazer, de residência), os modos de circulação específicos do mundo contemporâneo são passíveis de um olhar antropológico?" (AUGÉ, 1994, p.16-17)

É possível dizer que a pergunta não é apenas instigante; ela desperta também uma enorme sensação de mal-estar. A antropologia teria perdido as referências que a constituíram como ciência ou, ao contrário, essas mesmas referências necessitariam apenas de uma nova postura intelectual? O próprio

Rev. Mediações, Londrina, v. 4, n. 1, p. 14-19, jan./jun. 1999 
Marc Augé aponta respostas ao concordar em que é o outro o único tema da antropologia, o único meio pelo qual ela se realiza e se diferencia das demais ciências sociais. O outro deve ser visto pela antropologia em seus múltiplos aspectos, mesmo naqueles em que não há interseções aparentemente possíveis. O outro é, ao mesmo tempo, étnico, cultural, social, sexual, familiar, político, econômico, íntimo, e, enfim, um outro em relação a tantos outros. A representação do outro é individual e coletiva, não se dissocia, não se desfaz: é uma alteridade que, ao mudar, compreende toda uma totalidade de significados e representações. (idem, p.22-23)

A totalidade da qual se reveste o outro não deve ser confundida com culturas que produzem indivíduos iguais, semelhantes, desejosos das mesmas mudanças, que mudam em total e perfeita harmonia. Nesse outro que se totaliza existe o princípio preponderante da individualização, sem a qual toda e qualquer idéia de sobremodernidade seria natimorta. Nesse sentido, o outro - que é também o próximo num mundo de aceleração histórica e desenvolvimento transcontinental de mercados e utopias políticas - fornece à antropologia três novos conceitos a serem repensados e redimensionados: o tempo, o espaço e a individualização no mundo contemporâneo, no interior das tensas relações entre o que se faz globalmente e o que se produz localmente.

A noção de tempo remete todo o mundo aos grandes marcos do século XX. Não se pode mais crer em uma evolução da dignidade e da pureza humanas, radicadas num ponto ou noutro do globo, após as experiências traumáticas das grandes guerras tecnológicas e das revoluções que fomentaram a criação de Estados totalitários. A política dos Estados nesse século XX protagonizou espetáculos de genocídio, intolerância étnica e reduziu ao esquecimento os ideais humanistas do iluminismo e da filosofia clássica alemã. Os acontecimentos históricos - em razão da regressão das políticas públicas dos Estados modernos e da inaptidão desses mesmos Estados em assegurar uma vida digna a seus cidadãos - encurtaram os espaços e ocuparam um mundo que antes parecia tão vasto, impossível de ser visto a olho nu. A informação globalizada criou uma superabundância factual que integra, com maior ou menor intensidade, pontos distantes do planeta. A superabundância de acontecimentos históricos - as histórias individuais se tornam também historia da humanidade - suscita não apenas uma vontade humana de dar sentido ao mundo, mas também um problema que é em si de natureza da antropologia: os excessos que criam e recriam o tempo e o espaço. (idem, p.28-33)

No mundo contemporâneo, devido aos acontecimentos e fatos históricos que se multiplicam, torna-se difícil encurralar em um espaço qualquer uma noção exata de tempo. Em todos os espaços fixam-se imagens de satélites, sons e formas via computadores; ao mesmo tempo, esses espaços integram-se por meios de transporte cada vez mais sofisticados e velozes. Tudo o que se produz no mundo está mais próximo de cada um dos seres humanos, mesmo que se viva em cidades pequenas e em países igualmente pequenos, distantes, prosaicos. As informações e as mercadorias estão ao alcance de um clic no controle remoto da TV ou no mouse dos microcomputadores. Para esse mundo todas as sociedades vêm convergindo, abrindo e fechando suas fronteiras, selecionando o que lhes interessa, lhes apresenta algo de bom, substancial, aproveitável. Na expressão de Marc Augé, "um universo relativamente homogêneo em sua diversidade". (idem, p.34)

Tempo e espaço estão, portanto, revestidos de uma superabundância de história, histórias, reivindicações e resistências que não mais se acomodam, não mais se fixam, não mais demarcam territórios. $\mathrm{O}$ outro - anteriormente tão visível pelas suas raízes, pela sua língua, pelo seu lugar - agora está em trânsito pelo mundo. Os novos lugares são na verdade não-lugares, e às vezes não-lugares virtuais, informatizados, um universo em terceira dimensão.

O não-lugar é um espaço em que os indivíduos são acompanhados de uma profunda sensação de solidão, uma tensão solitária. (idem, p.87) Nas estradas, vias expressas, grandes lojas, supermercados, aeroportos, rodoviárias... os indivíduos não constroem identidades, não se relacionam, não se reúnem, não discutem problemas de comunidade... apenas circulam. Na Europa, é possível fazer uma viagem de Budapeste a Paris, de automóvel, e em todo o percurso não encontrar uma única pessoa: come-se diante de máquinas que engolem moedas e despejam salgados e refrigerantes, abastece-se o automóvel através de um sutil manuseio do cartão de crédito e repousa-se em hotéis que solicitam apenas o teclar do código de depósitos bancários. Em nenhum desses lugares há pessoas trabalhando e trocando experiências que a solidão traz em decorrência da distância de suas casas e cidades. $\mathrm{O}$ mundo moderno não é mais o lugar em que habitamos as cidades; habitamos o fluxo, o passar, o transitório, o momento que, amanhã ou depois, será passado.

Reaprender a olhar os espaços é refazer o olhar antropológico. (idem, p.38) Na sobremodernidade coexistem lugares e não-lugares, cuja aproximação é de essência política. Se o mundo (pós-)moderno acelera o trato exclusivo com os indivíduos (clientes, passageiros, consumidores, etc.), é desses mesmos indivíduos que depende o encontrar de suas vidas, o fixar idéias em novos lugares, espaços. Para tanto, torna-se imprescindível que se estabeleçam novos rumos para o debate sobre a cidadania, o Estado e a política democrática. Converter consumidores em cidadãos é tarefa política, e é também antropológica. Da democracia aprendemos que seus mais antigos dilemas não são insolúveis. Mas só serão viáveis - e aqui a antropologia tem um papel a desempenhar - no momento em que for rediscutida a questão da alteridade, do outro que a tantos se assemelha e, na mesma proporção, de tantos outros se distingue.

\section{CIDADANIA CULTURAL: ESPAÇOS PÚBLICOS EM QUE SE FALA DE DI- REITOS}

Se o homem em trânsito é um indivíduo que se separa dos demais, cuja vivência pessoal torna-o essencialmente um consumidor, o esfacelamento do Estado e das formas tradicionais de representação política e coletiva incentiva novos modelos de luta política através dos processos de reafirmação das culturas locais, das particularidades étnicas. Ser consumidor é 
reivindicar uma nova concepção de cidadania; é procurar criar e garantir novos direitos. É forte a afirmação de Paula Montero segundo a qual a cultura e suas múltiplas determinações no contexto da globalização transferem-se para o campo da luta política. (MONTERO, 1996, p.90)

O Estado moderno, palco das ações políticas institucionais que visam a enfraquecê-lo, sempre teve por característica fundamental a homogeneização dos espaços por ele administrados e supervisionados. Não é sem razão que se criam ideologias míticas com as expressões "povo brasileiro", "nação unida", "pátria de chuteiras", "um só povo, um só território, uma só língua", etc. Todas essas expressões difundidas e assimiladas como ideal de nação são parte da tentativa de construir uma identidade nacional e desfazer reivindicações de direitos que não estão em dia com a ordem jurídica dos acontecimentos. Limitar os direitos de cidadania aos motivos e alegações formais e jurídicos é inscrevêlos na imobilidade de sua própria existência, quer dizer, direitos são direitos na medida em que se movem, criam novas necessidades, procuram substituir e produzir novas formas de representação, novos modelos de sociabilidade. Pode-se dizer que a luta por direitos sociais e coletivos, no mundo moderno em movimento, tem na cultura a razão direta do Estado que se desfaz como nuvens em aviões e dos partidos políticos e sindicatos que perdem espaço para a chamada maximídia.

É comum a idéia de que os cidadãos do mundo contemporâneo se aproximam à medida que têm suas identidades constituídas e patrocinadas pelo consumo, por aquilo que no mundo todo se busca apreciar, ter como necessário, fundamental à existência, à "vida boa". A mundialização da cultura, entretanto, choca-se com o sincretismo dialético, porque entende por cultura somente os elementos relacionados com a publicidade, a música e a cultura de massa em geral. É uma definição cultural essencialmente mercadológica, voltada para os dizeres da globalização do mundo econômico; a cultura-mundo não dá conta dos processos pelos quais uma determinada cultura se refaz em face das relações econômicas e políticas globalizadas. (idem, p.9394)

A cultura que se refaz mediante a luta política pelos direitos de cidadania é uma cultura particular, que pretende assegurar sua existência e, ao mesmo tempo, confrontar-se num mundo democrático, de tolerância e respeito, com as demais alteridades sociais. Essa luta política tem um porquê e produz aos indivíduos e à própria antropologia um novo problema:

\footnotetext{
"A reivindicação (e o reconhecimento) de direitos supõe, em princípio, que os atores sociais se sintam parte de uma sociedade política mais abrangente do que aquela definida pelo seu pertencimento à rede de sociabilidades primárias (família, etnia, religião, etc.). No entanto, talvez esteja aí um dos nós górdios da questão da democracia do mundo contemporâneo: o enfraquecimento da capacidade dos sistemas democráticos de gerar sentimentos de pertencimento a coletividades mais abstratas organizadas em torno do reconhecimento de direitos." (idem, p.104-105)
}

Os dilemas da luta política e a crise dos sistemas democráticos trazem consigo o papel cada vez maior atribuído às subjetividades e o caráter abstrato das coletividades no mundo contemporâneo. Hoje, as identidades são extraterritoriais e multilingüísticas; necessitam de uma definição que as estabeleça num mundo em permanente comunicação, de permanentes e novas estratégias políticas que procuram definir de outros modos as identidades, agora tanto formais quanto informais, vinculadas e desvinculadas das raízes que outrora lhes garantiam a marca da diferença. (CANCLINI, 1997, p.35-36)

A idéia de uma cidadania cultural prevê não apenas a descoberta do que há de cultura na globalização, no mercado e no consumo, mas também aos cidadãos um novo vínculo de pertencimento que faça com que se possam assegurar as diferenças que existem entre aqueles que falam uma mesma língua, vivem sobre um mesmo território e são julgados e assistidos pelos mesmos aparelhos formais de justiça e representação. (idem, p.20-23) Se a cidadania dos meios jurídicos e das formas tradicionais de representação política é estatizante, tornase necessário, num universo preenchido por multiculturalidades, estabelecer um modelo democrático de cidadania que assegure a um só tempo os direitos à igualdade e à diferença. Para tanto, requer-se que pensemos num novo modelo de Estado no interior do qual se possa constantemente refazer a multiplicidade de reivindicações a partir de estratégias políticas que consigam unir as dimensões do mercado - da globalização econômica e da circulação transcontinental de imagens, sons, mercadorias... - e da política de construção de espaços públicos e políticos que se movimentam, que são sintetizados a toda a hora, a cada movimento que se faz em seu redor. É impossível, pois, desarticular as convergências que suscitam das mudanças perenes no sistema global dos mercados econômicos — as quais desencadeiam séries infinitas de novas necessidades de consumo - e das culturas e políticas que a partir do global se transformam e se tornam glocais. Não há superações; há diferentes leituras do que ocorre em toda a parte e se estabelece em localidades culturalmente determinadas. (cf. CANCLINI, 1997; AUGÉ, 1994; SANTOS, 1994; CANEVACCI, 1996)

Sobre a confluência entre cidadania, maximídia e consumo, e as necessidades que a partir dela se apresentam, escreve Néstor García Canclini:

\section{"A aproximação da cidadania, da comunicação de massa e do consumo tem, entre outros fins, reconhe- cer estes novos cenários de constituição do público e mostrar que para viver em sociedades democráticas é indispensável admitir que o mercado de opiniões cidadãs inclui tanta variedade e dissonância quanto o mercado da moda, do entretenimento. Lembrar que nós, cidadãos, também somos consumidores leva a descobrir na diversificação dos gostos uma das bases estéticas que justificam a concepção democrática de cidadania." (CANCLINI, 1997, p.34)}

O universo de investigação e reflexão da antropologia aumenta na medida em que se tornam viáveis as formas pelas quais se quer criar sociabilidades distintas no interior daquilo de que antes a fé e o Estado, nos tempos históricos 
em que eram construtores hegemônicos da identidade, quiseram ser únicos, reguladores, censores e, quiçá, redentores.

Para que o Estado e a sociedade não se tornem propriedade privada das vontades de um mercado que caminha incoerentemente rumo ao mundo de um só desejo - o de consumir - parece ser fundamental que a antropologia caminhe em direção a uma compreensão dos novos cenários socioculturais do mundo contemporâneo, quais sejam: o crescimento dos conglomerados empresariais e midiáticos em todo o mundo; a proliferação das manchas urbanas que a cada dia se tornam menos habitadas em virtude da fragilidade dos alicerces que sustentam a criação dos espaços públicos em que cidadãos possam se encontrar, discutir e, enfim, habitar suas casas e cidades; a invasão do alheio, do estranho, do distante, naquilo que antes se consumia e visualizava a partir de uma concepção regionalizada; a cultura-mundo, que não define cultura, mas espalha-se via TV, rádio, redes mundiais de computadores, criando movimentos cíclicos e efêmeros de modas que produzem comportamentos transnacionalizados; e a crescente idéia estereotipada e disseminada de um cidadão que não tem opiniões políticas, preocupando-se unicamente em qualificar a sua própria existência, o que torna antigas e descartáveis a experiência e a reflexão acerca dos problemas que atingem toda a sociedade e põe na ordem do dia tudo aquilo que a cultura do efêmero traz de supostamente importante, primordial para a realização de cada um de nós. (idem, p.27-28)

Vê-se que não são poucos nem simples os grandes desafios da antropologia no mundo contemporâneo. Há crises e mais crises que apontam fragilidades políticas, concepções distorcidas de cultura e tentativas novas de globalizar o ser humano, reduzi-lo a consumidor e espectador da grandiosidade de uma modernidade que se automovimenta. Quais lições oferecem o século XX para a antropologia do século XXI e quais as possibilidades que se apresentam?

\section{E VEM AÍ UM NOVO MILÊNIO...}

A antropologia do próximo século será profundamente marcada pelas experiências e acontecimentos históricos do século XX. O novo e o velho, o tradicional e o moderno, a razão e o mágico, tudo estará presente e justaposto das mais variadas formas. Lugares e não-lugares serão culturalmente sincretizados, "borrados", maculados por experiências culturais locais e constantemente atingidas por movimenos de ordem global e pretensamente totalizantes. A economia, 'a política e a ciência trarão avanços e retrocessos no que se refere às diferenças culturais; tentar-se-á criar novas concepções hegemônicas de democracia e buscar-se-á provar que o sincretismo não estabelece peculiaridades, e sim atravanca o progresso. O capital reconhecerá cada vez mais os oceanos pelos quais navega há 200 anos. Dir-se-á que não há mais utopias redentoras da condição humana, que estamos fadados a reconhecer o mundo das mercadorias como o único mundo possível: ou nele vivemos ou dele deixamos. Parece extremamente fecundo que a antropologia situe-se nos intervalos entre o pessimismo e o otimismo dessas premonições.
É da antropologia a difícil senda em que se verificará que o século XXI pode ser o terreno até então mais fértil para o seu desenvolvimento e para a compreensão de que, se o mundo se move, é porque os homens e suas autoconstruções culturais o fazem, sem parar, às vezes sem entender — ou pouco entender, de imediato entender - , mas é fato que o movem. E como o movem!

"O século XXI será antropológico, não só porque as três figuras do excesso [tempo, espaço e individualização] não são senão a forma atual de uma matéria-prima perene, que é a própria matéria da Antropologia, mas também porque, nas situações de sobremodernidade, (...) os componentes se somam sem se destruírem. Assim, pode-se antecipadamente tranqüilizar aqueles apaixonados pelos fenômenos estudados pela Antropologia (da aliança à religião, da troca ao poder, da possessão à feitiçaria): eles não estão perto de desaparecer, nem na África nem na Europa. Mas farão sentido novamente (farão novamente o sentido) com o resto, num mundo diferente cujas razões e desrazões os antropólogos de amanhã terão que compreender, como hoje." (AUGÉ, 1994, p.42)

\section{NOTA}

\footnotetext{
'O termo glocal é utilizado por Massimo Canevacci para designar um sincretismo extraterritorial em que as travessias entre correntes opostas - movimentos culturais de todo o mundo, contato e informação em escala mundial — criam temperaturas, ansiedades, angústias e, sobretudo, respostas diferentes. O sincretismo cultural num mundo de características cada vez mais glocais não é linear, mas sim um modelo descentrado, particular, uma história que cria sínteses particulares entre o que é próprio e o que é alheio a uma determinada cultura. (ver CANEVACCI, 1996, p.23-25)
}

\section{REFERÊNCIAS BIBLIOGRÁFICAS}

ARENDT, Hannah. Da revolução. São Paulo/Brasília: Ática/UnB, 1990.

AUGÉ, Marc. Não-lugares. Introdução a uma antropologia da supermodernidade. São Paulo: Papirus, 1994.

"Agora somos todos contemporâneos". Sexta-feira, n.3, p.112119, out. 1998. Entrevista concedida a Paula Miraglia.

CANCLINI, Néstor García "Consumidores do século XXI, cidadãos do século XVII". In: Consumidores e cidadãos: conflitos multiculturais da globalização. Rio de Janeiro: Ed. UFRJ, 1997.

CANEVACCI, Massimo. Sincretismos: uma exploração das hibridações culturais. São Paulo: Studio Nobel/Instituto Cultural Ítalo-Brasileiro/ Istituto Italiano di Cultura, 1996.

MONTERO, Paula. "Reflexões sobre uma antropologia das sociedades complexas". Revista de Antropologia, v.34, p.103-130, 1991.

"Cultura e democracia no processo da globalização". Novos Estudos Cebrap, n.44, p.89-114, mar. 1996.

SANTOS, Boaventura. de S. "Modernidade, identidade e a cultura de fronteira". Tempo Social - Revista de Sociologia da USP, v.5, n.1-2, p.3152 , nov. 1994. 